\title{
The New Statutes of the University of Cambridge.
}

THE statutes of the University of Cambridge proposed by the University Commissioners were made public about a week ago. They occupy no less than sixty-nine pages of the University Reporter. Throughout they afford ample evidence of careful drafting, the final result of much deliberation and discussion.

We are not here concerned with such changes as the institution of a house of residents, or with the fact that in future the vice-chancellor is to be elected for a period of two years in the first instance, but rather with such proposals as will affect the various departments of science in the University. In many ways the proposed organisation will change scientific faculties far less than others. Each science school has been a financial unit for a long time; it has in practice organised all formal teaching in its own subject, and the more junior appointments (that is, demonstratorships) have been made by the professor. In most other branches of study, however, much has in the past been done by the colleges. They have financed and appointed their own lecturers, professors having no direct control in the matter. Until recent years many courses of college lectures were not immediately available to members of all colleges. Under the new scheme all formal teaching will be directly controlled by the University.

In the past the General Board of Studies was the co-ordinating body, and it worked through a system of special boards. Membership of the latter might be ex officio as in the case of professors, readers, and examiners, or upon nomination by the Council of the Senate, or by grouped junior members of departments. In the future there is to be a general board of the faculties with the powers of the old board, and in addition (presumably subject to the approval of the financial board) control of the salaries of the junior appointments. Eight of its thirteen members are to be elected by the faculty boards. Special boards are to be replaced by faculty boards, membership of which, ex officio, is limited to professors or heads of departments. Elected members are to be chosen by ballot at a general meeting of the faculty concerned.

These changes are important, because the powers of the new bodies are considerably greater than those of their predecessors. In addition to routine work, they will elect members of the new appointments committees which will appoint lecturers and demonstrators; they will have the power to institute and appoint to probationary lectureships, and to make recommendations to the general board on the subject of the salaries of the junior members of the staffs. From this system an increased uniformity in the scientific departments should result. In the past, the larger and less embarrassed departments have often been able to grant their staffs higher emoluments than have some of those the finances of which were more straitened. There is a prospect that the co-ordinating general board will now be in a position to ensure for equal work a reasonably uniform standard of remuneration in all faculties and departments.

It is difficult to forecast future events, but the intention of the Commissioners has evidently been to frame a constitution by which the junior members of a faculty can have the opportunity of securing reasonable representation on their board. Past experience has shown that, in the matter of nominating members of special boards, the junior staffs are often as apathetic as is the ordinary man in electing guardians of the poor. The Commission proposes to ensure that the machinery shall be there. They can do no more.

It may appear that undue stress has been laid on the financial powers of various bodies; but the strength of the University largely depends on its retaining the younger men most fitted for its purposes and in the past this has sometimes, for financial reasons, been difficult. The stipends of junior members of staffs are usually small, and unless accompanied by fellowship dividends are scarcely sufficient to allow a man to marry unless he happens to have private means. Outside work of some kind or other is usually obtainable, but frequently so much of it has to be done that there is little time left for the all-important research. The Commissioners are endeavouring to avoid this evil by making colleges reserve a proportion of fellowships for University officials, and further by permitting extra remuneration to be made to non-fellows. Time will show whether there is enough money available to implement these policies.

If the necessary funds are lacking, some non-fellows will be in a difficult position, as the University Commissioners, in their endeavour to avoid "sweating," have laid down a maximum number of hours of private teaching which may not be exceeded by university officers. A probationary lecturer giving one course of lectures, for which he will be entitled to draw a "basic" salary of about $\mathrm{r} 60 \mathrm{l}$., will, if he is not a fellow of a college, find little by way of gilt on his gingerbread. The whole financial situation is obscure; faculties controlling few students will presumably have to be subsidised from the University exchequer, as are some scientific departments at the present time. It will be interesting to observe if any faculty can provide a surplus. Expected surpluses have a way of failing to materialise.

The conditions of tenure of various offices are to be changed. Professors are to retire at the age of sixty-five. This decision has been arrived at after several changes of policy. The original commission advocated it. The present one, after publishing an interim account of its intentions, in which it stated that it would increase the retiring age to seventy in certain circumstances, has now reverted to the first proposal. This change of plan threatens to do an injustice to any recently appointed professors who, assuming that seventy was the final decision, on accepting their new posts agreed to come under the provisions of the new statutes. Presumably adjustments will have to be made in such cases.

Lectureships are to be tenable for three years in the first instance, but on reappointment they are in general to continue until the retiring age. "There are some who consider that this security of tenure may lead to doubtful efficiency, but as a lecturer's stipend will in the future depend chiefly on the amount of work he does in the department, their fears are probably groundless.

Demonstrators are to be appointed for three years, and are in no case to hold office for more than eight years. The underlying idea is that at the end of the latter period the faculty board will have to face the necessity of creating a new lectureship for a man if it wishes to retain his services. This will mean that each case will be carefully scrutinised; men of uncertain value will be sorted out on the one hand, and on the other, those of ripe middle age and undoubted distinction will no longer have to carry the somewhat juvenile title of demonstrator. On paper it seems as

No. 2923 , vOL. I 16$]$ 
if the whole scheme should work satisfactorily provided that it is not beyond the limits of the University chest.

A change is contemplated in the organisation of biological faculties. The old special board of biology and geology consisted of twenty-eight members. Under the new scheme there will be two faculties, namely, Biology " A," including anatomy, botany, genetics, geology, parasitology, and zoology, and Biology " $\mathrm{B}$," comprising biochemistry, pathology, physiology, with experimental psychology added. For certain purposes a "School of Biological Sciences" will be formed. It seems a little doubtful if any good result will be achieved by this splitting of what was a fairly natural grouping, if a large one.

The primary duty of the Commission was to adjust the relations of the University and the colleges; this has been done not only in the provision of reserved fellowships and in the centralisation of teaching activities, but also in the matter of contributions from the colleges to the University chest. In the past, the colleges together have had to pay such a percentage of their combined incomes as provided the sum of $30,000 l$. per annum. In the future, definite rates of taxation are proposed by which the poorer colleges will pay less and the larger ones will pay more than heretofore. On the other side, the colleges are relieved from paying contributions on income derived from students. There are adjustments to be made during the transition period, and a rough calculation suggests that at first the sum due from collegiate sources will not greatly exceed the $30,000 l$. As the new order comes in, there should be an increasing sum available, and further, as colleges become more wealthy owing to benefactions or husbanded resources, the University will in its turn be able to expand its activities. It is too much to hope that the University will ever cease to be an active beggar, but the anomaly of the underpaid university officer serving through a university organisation the requirements of colleges, some outstandingly wealthy, should be removed.

\section{International Meteorological Research.}

THE Meteorological Section of the International Union of Geodesy and Geophysics met at Madrid at the beginning of October I924, and the proceedings of the Section edited by the secretary, Prof. Eredia, have now been published. Some doubt had been felt by those familiar with international meteorological organisation as to whether the Meteorological Section of the Geophysical Union could find a broad enough field of operations without encroaching upon the proper domain of the International Meteorological Committee. The report of the work of the Section at Madrid which is contained in the present volume ought to remove any doubt of this kind. There are points where the work of the Section touches the work of the International Meteorological Committee, and under the guidance of a president less familiar than Sir Napier Shaw with international meteorological organisation, the Section might have wasted a certain amount of time in the unprofitable discussion of questions belonging to the field of official administration. The minutes of the five meetings, one of which was held conjointly with the Sections of Hydrology, Oceanography and Terrestrial Magnetism, show that the Commission confined itself to the encouragement and development of experimental and exploratory work in meteorology.

One of the most important decisions, afterwards confirmed by the Union in general session, was to provide for the issue of a specimen volume of the observations of the upper atmosphere for a single vear, collected from all the world. It is understood that this volume is now in course of preparation, and will represent a great advance not only in regard to the number of observations included but also more especially in regard to their presentation for scientific discussion.

Another important decision arose out of a discussion on the question of the establishment of an International Bureau. It was decided to make a subvention to an existing meteorological service for the execution of a piece of work of the kind that an International Bureau might be expected to undertake. Mr. la Cour, director of the Danish Meteorological Institute, was entrusted with the work selected, which consists in the preparation of an atlas of daily or twice daily synoptic charts for as large a portion as possible of the Northern Hemisphere for the third quarter of the year 1923 .
The appendices to the proceedings contain some interesting proposals and some valuable data. The American delegates presented, among other things, a proposal to adopt Dr. Marvin's suggestion for improving the Gregorian calendar. The suggestion is, briefly, to have a year of 13 months and a quarter of $I_{3}$ weeks. There would be an odd day to dispose of in ordinary years and 2 days in leap years. The Commission approved of having 52 weeks in the year, one of the weeks being a week of 8 days, and decided to recommend the Advisory and Technical Committee on Communications and Transit of the League of Nations to take into consideration as soon as possible the simplification of the Gregorian calendar. In a matter of this kind there does not appear to be special need for urgency; the need appears to be rather for discussion and deliberation. A change in the calendar is, and ought to be, an infrequent event, but when a change is made it ought to be as much of an advance as humanity can stand. It seems a pity that the Commission did not tackle the question of the length of the week ; it is fundamental. There appears to be no reason why the 7-day arrangement which commended itself to pastoral oriental people 3000 years ago should be suited to western urban civilisation of to-day. Many facts indicate that it is not. A break at the end of 6 days is too soon for the man who has a piece of work in which he is really interested; it is too late for the man who is not specially interested in his work. Consequently the latter, nowadays, usually has a mid-week half-holiday. A ro-day week with a secular mid-week holiday might be better for all concerned. It would save us from the numerical inconvenience and the ill omen of $\mathrm{I}_{3}$ months in the year.

Another appendix deals with the subject of radiation in relation to meteorology. A table giving the radiation of black earth at various temperatures will prove most useful for reference by all students of meteorology and ought to find its way into all standard collections of meteorological tables. The tabulated values of actual radiation recorded at various places, given on pp. 94- $2 \mathrm{I}$, provide the first systematic collection of observations of radiation, and their issue should lead to the adoption of an international form for the publication of such records in future. The variety of forms and units now in use is an obstacle to research which might well be removed. 